\title{
Li self-diffusion in lithium niobate single crystals at low temperatures
}

\author{
J. Rahn, ${ }^{a}$ E. Hüger, ${ }^{a}$ L. Dörrer, ${ }^{a}$ B. Ruprecht, ${ }^{b c}$ P. Heitjans ${ }^{b c}$ and H. Schmidt ${ }^{* a c}$ \\ Received 11th November 2011, Accepted 22nd December 2011 \\ DOI: $10.1039 / \mathrm{c} 2 \mathrm{cp} 23548 \mathrm{j}$
}

Li self-diffusion in $\mathrm{Li}_{2} \mathrm{O}$-deficient $\mathrm{LiNbO}_{3}$ single crystals is investigated in the temperature range between 423 and $773 \mathrm{~K}\left(150-500{ }^{\circ} \mathrm{C}\right)$ by secondary ion mass spectrometry. A thin layer of ionbeam sputtered isotope enriched ${ }^{6} \mathrm{LiNbO}_{3}$ was used as a tracer source, which allows one to study pure isotope interdiffusion. The diffusivities can be described by the Arrhenius law with an activation enthalpy of $(1.33 \pm 0.03) \mathrm{eV}$, which is in acceptable agreement with the migration energy of a single Li vacancy as determined by ab initio calculations given in the literature. Charge diffusivities as derived from impedance spectroscopy measurements on the same type of samples are identical to the tracer diffusivities within error limits. No indication of the formation of defect-complexes at low temperatures could be found in the diffusion behaviour.

\section{Introduction}

Lithium niobate $\left(\mathrm{LiNbO}_{3}\right)$ is one of the most technologically important oxides, with an extraordinary combination of ferroelectric, piezoelectric, acoustic, optical as well as ion conducting properties. ${ }^{1-3}$ Large ferroelectric, pyroelectric and piezoelectric coefficients are present due to the polar asymmetry of the $\mathrm{Li}-\mathrm{O}$ cage in the hexagonal crystal structure (space group $R 3 c) .{ }^{4-6} \mathrm{LiNbO}_{3}$ exhibits a wide solid solution region ranging from $44 \mathrm{~mol} \%$ to about $50.5 \mathrm{~mol} \% \mathrm{Li}_{2} \mathrm{O}{ }^{7}$ Single crystals produced by the Czochralski method commonly show the congruent composition of about $48.5 \mathrm{~mol} \% \mathrm{Li}_{2} \mathrm{O}$. However, by using the vapor transport equilibration (VTE) method the synthesis of near stoichiometric crystals is also possible. ${ }^{8}$ The change of composition from the lithium-poor compositions to the stoichiometric composition results in significant changes in the physical properties of the system, including the Curie temperature, the ferroelectric coercive field, and photorefractive properties. ${ }^{1,9}$ These changes in physical properties are expected to be the result of defect clusters, which are also responsible for the non-stoichiometry. Several defect models are proposed, ${ }^{2,8,10-14}$ while for the realization of the congruent composition the most reliable model consists of a niobium antisite atom which is compensated by four lithium vacancies $\left(\mathrm{Nb}_{\mathrm{Li}}^{\circ \cdots \bullet}+4 V_{\mathrm{Li}}^{\prime}\right){ }^{13}$ In contrast, at and close to the stoichiometric composition Li Frenkel defects are expected. ${ }^{13}$

For many applications of lithium niobate, self-diffusion of the constituents is of high importance. Especially, the formation,

${ }^{a}$ Institut für Metallurgie, Thermochemie und Mikrokinetik, Technische Universität Clausthal, Clausthal-Zellerfeld, Germany. E-mail: harald.schmidt@tu-clausthal.de

${ }^{b}$ Institut für Physikalische Chemie und Elektrochemie,

Leibniz Universität Hannover, Hannover, Germany

${ }^{c}$ ZFM-Zentrum für Festkörperchemie und Neue Materialien,

Leibniz Universität Hannover, Hannover, Germany stability and dissociation of defect clusters are closely related to diffusion properties. Further, it is of considerable interest ${ }^{13}$ whether the defect clusters are expected to be long lived or whether the energy barriers to Li vacancy migration are sufficiently low so that the defect clusters might be highly dynamic, with Li vacancies diffusing among the various nearly energetically equivalent sites. If the defects are dynamic, the non-uniaxial components of the polarization of each individual cluster may dynamically cancel out locally. ${ }^{13}$ Furthermore $\mathrm{Li}$ diffusivities are a measure for ionic transport properties and consequently for the ion conductivity.

While numerous studies on impurity diffusion are available for single crystalline $\mathrm{LiNbO}_{3}$, reliable data on $\mathrm{Li}$ self-diffusion are very rare (for a review see ref. 13 and 15). $\mathrm{Li}$ is expected to be the most mobile species. Diffusion experiments are restricted to nuclear magnetic resonance (NMR) studies and also to impedance spectroscopy, ${ }^{15-23}$ while most of the data are limited to the high temperature range above $773 \mathrm{~K}$. There, diffusion is very fast and the defect complexes are destabilized. The only diffusion study based on mass tracers and stable isotopes was restricted to high temperatures above $1000 \mathrm{~K} .^{15,24}$ Besides an ion conductivity study ${ }^{16,21}$ no diffusivity data are available for single crystals below $773 \mathrm{~K}$. An open question now is whether the diffusion mechanism at low and high temperatures is the same or whether it is changing due to the formation/ dissociation of defect complexes or other processes.

In the present work, we investigated $\mathrm{Li}$ self-diffusion in $\mathrm{L}_{2} \mathrm{O}$-deficient $\mathrm{LiNbO}_{3}$ single crystals in the temperature range between 423 and $773 \mathrm{~K}$ using secondary ion mass spectrometry. We used isotope enriched ${ }^{6} \mathrm{LiNbO}_{3}$ as a tracer reservoir. A sketch of the experimental arrangement is given in Fig. 1, where a thin isotope enriched layer of ${ }^{6} \mathrm{LiNbO}_{3}$ is deposited on the single crystal under investigation. The use of so-called isotope hetero-structures is an extremely reliable method to study self-diffusion processes in solids because pure isotope 


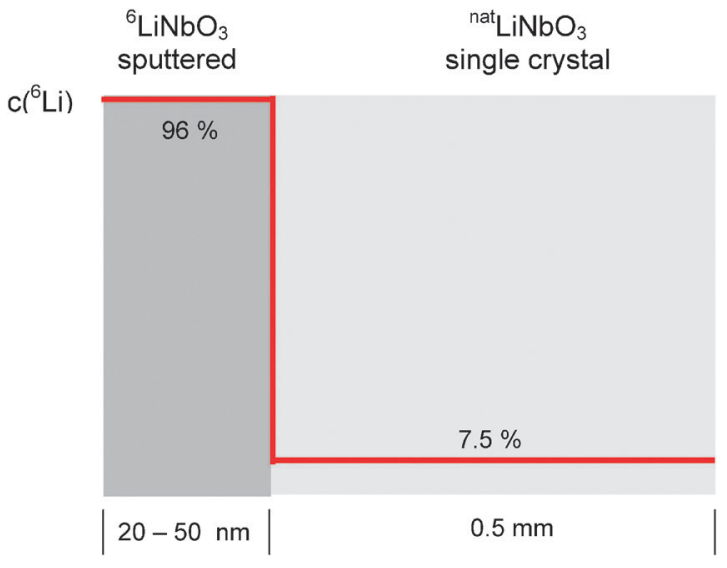

Fig. 1 Schematic representation of the diffusion experiment: $20-50 \mathrm{~nm}$ of $\mathrm{LiNbO}_{3}$, composed of $96 \%{ }^{6} \mathrm{Li}$ and $4 \%{ }^{7} \mathrm{Li}$ (termed ${ }^{6} \mathrm{LiNbO}_{3}$ ), is deposited via ion beam sputtering on a $\mathrm{LiNbO}_{3}(0001)$ single crystal, composed of $7.5 \%{ }^{6} \mathrm{Li}$ and $92.5 \%{ }^{7} \mathrm{Li}$ isotopes (termed ${ }^{\text {nat }} \mathrm{LiNbO}_{3}$ ).

interdiffusion takes place undisturbed from chemical gradients. ${ }^{25-29}$ For comparison and in order to further elucidate details of the atomic transport properties, additional impedance spectroscopy measurements were done on the same type of single crystal.

\section{Experimental details}

The $\mathrm{LiNbO}_{3}$ single crystals under investigation were supplied by Crystec (Berlin, Germany). The chemical composition was determined by UV absorption spectroscopy according to ref. 30 and 31. $\mathrm{A} \mathrm{Li}_{2} \mathrm{O}$ content of $(48.5 \pm 0.1) \mathrm{mol} \%$ was found which corresponds to the congruent composition of the phase diagram. $10 \times 10 \times 0.5 \mathrm{~mm}^{3} c$-axis oriented polished pieces were used for the experiments. Tracer deposition was carried out by depositing a $20-50 \mathrm{~nm}$ thin layer of isotope enriched ${ }^{6} \mathrm{LiNbO}_{3}$ on the single crystal by ion beam sputtering, using a commercial set-up (IBC 681, Gatan) equipped with two Penning ion sources. Deposition was done at $5 \mathrm{keV}$ and a current of about $200 \mu \mathrm{A}$ in argon at an operating pressure of $5 \times$ $10^{-3}$ mbar. The base vacuum was better than $5 \times 10^{-7}$ mbar.

The sputter targets were prepared by solid state syntheses. Coarse $\mathrm{Nb}_{2} \mathrm{O}_{5}$ from Alfa Aesar (99.95\%) was pestled to a fine powder in an agate mortar and mixed with enriched ${ }^{6} \mathrm{Li}_{2} \mathrm{CO}_{3}$ from Eurisotop $\left(96 \%{ }^{6} \mathrm{Li}\right)$. In order to account for loss of lithium in the sputtering process, the molar ratio of oxide and carbonate was chosen as $5: 6$. This results in targets of the composition $90 \%{ }^{6} \mathrm{LiNbO}_{3}+10 \%{ }^{6} \mathrm{Li}_{3} \mathrm{NbO}_{4}$. After subsequent ball milling of the powder mixture in a SPEX $8000 \mathrm{M}$ shaker mill, pellets of $2 \mathrm{~cm}$ in diameter were pressed and heated to $973 \mathrm{~K}$ with a rate of $2 \mathrm{~K} \mathrm{~min}^{-1}$. The reaction step was followed by a sintering process at $1173 \mathrm{~K}$ for $12 \mathrm{~h}$, which yielded polycrystalline dense targets. After tracer deposition, the sputtered layer consists of single phase $\mathrm{LiNbO}_{3}$. This was proven by Grazing Incidence X-ray diffractometry on a $300 \mathrm{~nm}$ thin film which was annealed at $600{ }^{\circ} \mathrm{C}$. Annealing induces crystallization and the formation of a polycrystalline film. No secondary phases (e.g. $\mathrm{Li}_{3} \mathrm{NbO}_{4}$ or $\mathrm{LiNb}_{3} \mathrm{O}_{8}$ ) were detected. Due to the fact that the tracer layer and single crystal have approximately the same chemical composition pure isotope interdiffusion is expected to be measured during the diffusion experiments.
For the diffusion experiments the coated samples were placed in a silica glass holder and introduced in the hot zone of a resistance furnace under ambient air conditions. The annealing time was between $30 \mathrm{~min}$ and 184 days at temperatures between 673 and $423 \mathrm{~K}$. Additional diffusion annealing experiments were carried out in a commercial rapid thermal annealing setup (AO 500, MBE, Germany) in argon between 673 and $773 \mathrm{~K}$. Here, extremely high heating rates are possible which allow one to realize annealing times down to several seconds.

The inward diffusion of the ${ }^{6} \mathrm{Li}$ from the sputter layer into the single crystal was determined by secondary ion mass spectrometry (SIMS) using a CAMECA IMS-3F machine. An $\mathrm{O}^{-}$primary ion beam $(15 \mathrm{keV}, 25 \mathrm{nA})$ was used in order to prevent electrical charging during the measurement. The sputtered area was about $250 \mu \mathrm{m} \times 250 \mu \mathrm{m}$. For further processing in a double focused mass spectrometer, the signal resulting from an area of about $110 \mu \mathrm{m} \times 110 \mu \mathrm{m}$ in the centre was used in order to exclude effects resulting from the crater edge.

In the depth profiling mode, the secondary ion intensities of ${ }^{6} \mathrm{Li}^{+}$and ${ }^{7} \mathrm{Li}^{+}$ions were recorded as a function of sputter time. Since the two $\mathrm{Li}$ isotopes are chemically identical (neglecting the small isotope effect) for diffusion analysis the intensity of the signals is converted into ${ }^{6} \mathrm{Li}$ atomic fractions $c(x, t)$ according to

$$
c(x, t)=\frac{I\left({ }^{6} \mathrm{Li}\right)}{I\left({ }^{6} \mathrm{Li}\right)+I\left({ }^{7} \mathrm{Li}\right)}
$$

Depth calibration was obtained by measuring the crater depth with a mechanical profilometer (Tencor, Alphastep).

For the impedance spectroscopy measurements single crystal slices with dimensions of $10 \times 10 \times 0.4 \mathrm{~mm}^{3}$ were polished on both sides. Plane-parallel circular Ag electrodes of $5 \mathrm{~mm}$ in diameter were applied using silver conductive adhesive paste from Alfa Aesar. After drying the sample at $383 \mathrm{~K}$ additional $\mathrm{Pt}$ sheet contacts were glued on both sides with the same silver paste and fixed in a second drying step. Such electrodes withstand temperatures of $1000 \mathrm{~K}$ with no signs of damage.

$\mathrm{AC}$ impedance measurements in the frequency range from $5 \mathrm{~Hz}$ to $13 \mathrm{MHz}$ with an alternating voltage of $0.125 \mathrm{~V}$ were carried out with a Hewlett Packard 4192A impedance analyzer and a home-built cell in air. A spring mechanism ensured that the sample was reliably connected to the jig. Temperature was measured using a type $\mathrm{K}$ thermocouple attached close to the sample and a Eurotherm temperature controlling unit.

\section{Results}

The ${ }^{6} \mathrm{Li}$ atomic fraction as a function of sputter depth is given in Fig. 2 for as-deposited samples annealed at $523 \mathrm{~K}$ for various times. With increasing annealing time the ${ }^{6} \mathrm{Li}$ tracer penetrates into the single crystal to depths of more than $200 \mathrm{~nm}$. Experimentally determined depth profiles broadened after annealing can be described by the following solution of Fick's second law for self-diffusion across an interface ${ }^{32}$

$$
c(x, t)=c_{\infty}+\frac{\left(c_{0}-c_{\infty}\right)}{2}\left[\operatorname{erf}\left(\frac{h+x}{R}\right)+\operatorname{erf}\left(\frac{h-x}{R}\right)\right],
$$




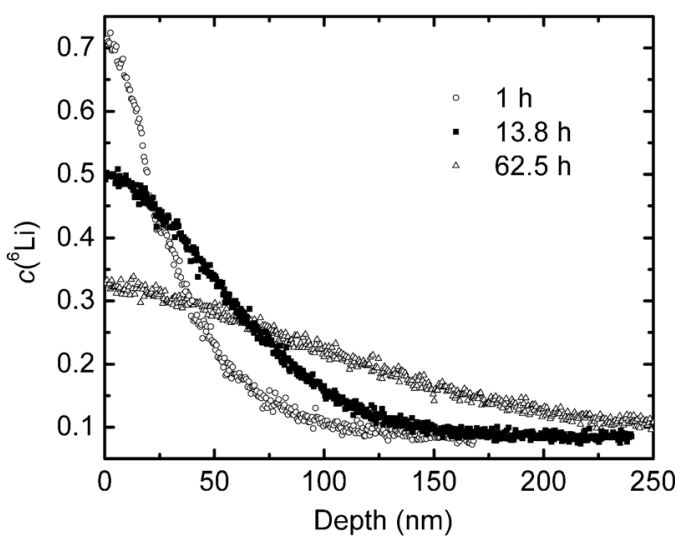

Fig. 2 Atomic fraction of ${ }^{6} \mathrm{Li}$ as a function of depth for a sample annealed at $523 \mathrm{~K}$ for $1,13.8$ and $62.5 \mathrm{~h}$.

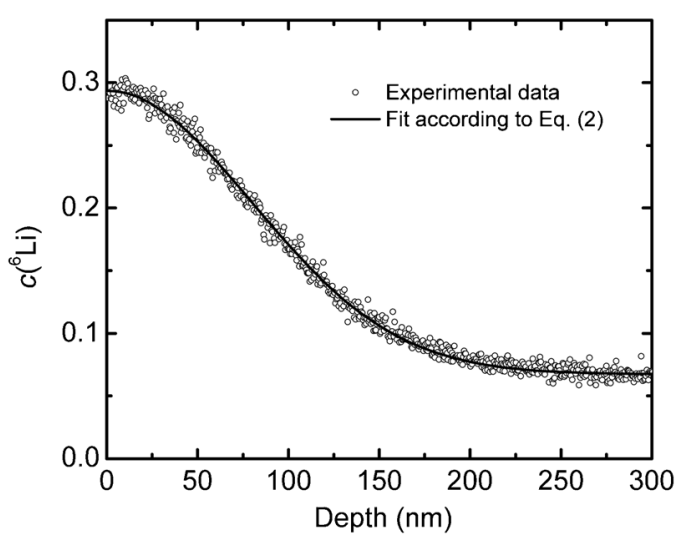

Fig. 3 Atomic fraction of ${ }^{6} \mathrm{Li}$ as a function of depth after annealing at $473 \mathrm{~K}$ for 34 days. A least-squares fit of eqn (2) to the experimental data is also indicated $\left(c_{\infty}=0.075, c_{0}=0.96, h=24 \mathrm{~nm}, R=111 \mathrm{~nm}\right)$.

where $c_{\infty}=0.075$ is the natural abundance of ${ }^{6} \mathrm{Li}$ in the single crystal and $c_{0}=0.96$ that in the tracer layer. The original thickness of the as-deposited tracer layer is denoted as $h$, which was determined by SIMS to range between $20-50 \mathrm{~nm}$, depending on the sample under investigation. The quantity $R$, describing the broadening of the tracer profile, is treated as a fit parameter. The self-diffusivity $D$ at time $t$ is determined from the difference in $R$ of the diffusion profile and of the starting profile according to $D=\left(R^{2}(t)-R^{2}(0)\right) / 4 t$. A typical example for an experimentally determined isotope depth profile and the corresponding fit is given in Fig. 3.

For the determination of diffusivities samples were used where the tracer significantly (at least $50 \mathrm{~nm}$ ) penetrated into the single crystal (see Table 1). This was done in order to minimize possible fitting errors, which may result from low diffusion lengths. An overview on the results of the fitting procedures for all measurements is given in Table 1. It illustrates that no time dependence of diffusivities can be observed within error limits. An additional experiment was carried out, where a single crystal was pre-annealed at $1223 \mathrm{~K}$ $\left(950{ }^{\circ} \mathrm{C}\right)$ for $12 \mathrm{~h}$ before tracer deposition and afterwards diffusion annealed for $61.4 \mathrm{~h}$ at $523 \mathrm{~K}\left(250{ }^{\circ} \mathrm{C}\right)$. The determined diffusivity of $2.2 \times 10^{-20} \mathrm{~m}^{2} \mathrm{~s}^{-1}$ is identical within error limits to the value given in Table 1 .
Table 1 Compilation of the parameters of the diffusion experiment, where $T$ is the annealing temperature, $t$ is the annealing time, $R$ is the diffusion length obtained from the fit, and $D$ is the lithium diffusivity. Typical relative errors attributed to the diffusivities from the fitting of eqn (2) are about $30 \%$

\begin{tabular}{lllcl}
\hline$T / \mathrm{K}$ & $T /{ }^{\circ} \mathrm{C}$ & $t$ & $R / \mathrm{nm}$ & $D / \mathrm{m}^{2} \mathrm{~s}^{-1}$ \\
\hline 423 & 150 & $35 \mathrm{~d}$ & 33 & $3.8 \times 10^{-23}$ \\
423 & 150 & $184 \mathrm{~d}$ & 48 & $2.6 \times 10^{-23}$ \\
448 & 175 & $593 \mathrm{~h}$ & 55 & $2.9 \times 10^{-22}$ \\
473 & 200 & $144 \mathrm{~h}$ & 53 & $1.2 \times 10^{-21}$ \\
473 & 200 & $816 \mathrm{~h}$ & 111 & $1.0 \times 10^{-21}$ \\
523 & 250 & $13.8 \mathrm{~h}$ & 80 & $2.8 \times 10^{-20}$ \\
523 & 250 & $62.5 \mathrm{~h}$ & 129 & $1.8 \times 10^{-20}$ \\
573 & 300 & $3 \mathrm{~h}$ & 112 & $1.8 \times 10^{-19}$ \\
623 & 350 & $0.5 \mathrm{~h}$ & 112 & $1.7 \times 10^{-18}$ \\
623 & 350 & $2.5 \mathrm{~h}$ & 227 & $1.4 \times 10^{-18}$ \\
673 & 400 & $5 \mathrm{~min}$ & 171 & $2.4 \times 10^{-17}$ \\
673 & 400 & $30 \mathrm{~min}$ & 351 & $1.9 \times 10^{-17}$ \\
723 & 450 & $75 \mathrm{~s}$ & 178 & $1.0 \times 10^{-16}$ \\
773 & 500 & $15 \mathrm{~s}$ & 206 & $6.9 \times 10^{-16}$ \\
\hline
\end{tabular}

In Fig. 4 the determined tracer diffusivities are plotted as a function of reciprocal temperature. For temperatures for which more than one diffusion anneal was carried out, the value with the largest broadening in $R$ is displayed in Fig. 4. The data obey the Arrhenius law

$$
D=D_{0} \exp \left(-\Delta H / k_{\mathrm{B}} T\right)
$$

A least-squares fit of eqn (3) to the diffusivities results in an activation enthalpy of $\Delta H=(1.33 \pm 0.03) \mathrm{eV}$ and a pre-exponential factor of $D_{0}=1.7 \times 10^{-7} \mathrm{~m}^{2} \mathrm{~s}^{-1}$ (error: $\left.\ln D_{0} / \mathrm{m}^{2} \mathrm{~s}^{-1}= \pm 0.8\right)$ in the temperature range between 423 and $773 \mathrm{~K}$. Note that the diffusivities vary over almost eight orders of magnitude.

Fig. 5(a) shows the ac conductivity as a function of frequency of a $\mathrm{LiNbO}_{3}$ single crystal for temperatures between $776 \mathrm{~K}$ and $880 \mathrm{~K}$. In the Cole-Cole plot of Fig. 5(b),

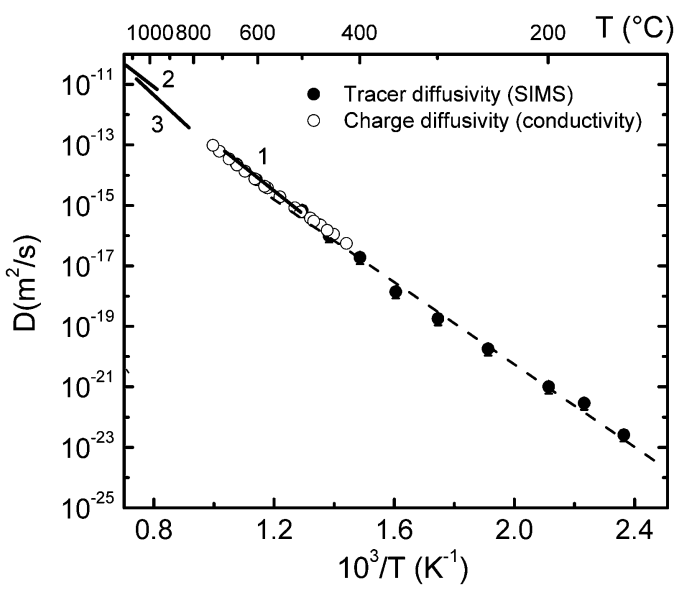

Fig. 4 Diffusivities of $\mathrm{Li}$ in a $\mathrm{LiNbO}_{3}$ single crystal as a function of reciprocal temperature. Shown are tracer diffusivities measured by SIMS and charge diffusivities obtained by conductivity measurements. In the case of conductivity measurements, eqn (4) is used to calculate charge diffusivities. The dashed straight line corresponds to the Arrhenius fit of the SIMS data. For comparison, literature data taken from ref. 15 are given in the form of straight lines according to the following original references: (1) Halstead (NMR), ${ }^{19}$ (2) Mehta et al. (ion conductivity) ${ }^{20}$ and (3) Ptashnik et al. (tracer). ${ }^{24}$ 

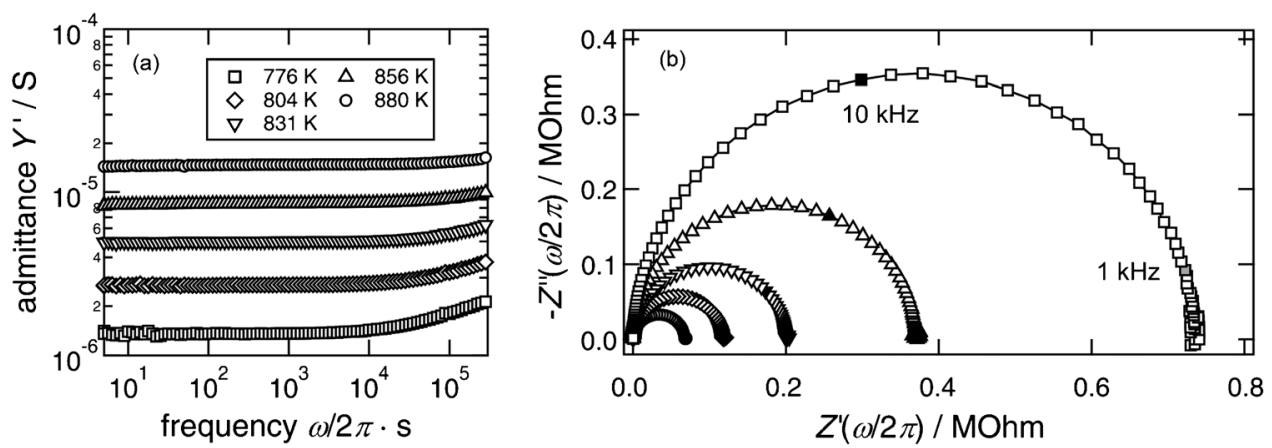

Fig. 5 (a) Real part of the admittance of a $\mathrm{LiNbO}_{3}$ single crystal as a function of frequency for temperatures between $776 \mathrm{~K}$ and $880 \mathrm{~K}$. (b) $-Z^{\prime \prime}(\omega)$ vs. $Z^{\prime}(\omega)$ plot (Cole-Cole plot).

$-Z^{\prime \prime}(\omega)$ against $Z^{\prime}(\omega)$, a single impedance arc is observed. A circle fit reveals a low inclination of less than 2 degrees for all temperatures. Accordingly, only low dispersion occurs in the admittance spectra $Y^{\prime}(\omega)$ at high frequencies. An ideal Debye behavior which can be modeled by a single RC element with a single conductivity relaxation time $\tau=R C$ would result in perfect semicircles and a frequency independent value of $Y^{\prime}(\omega)$, respectively. In contrast, for real ionic conductors dispersive, i.e. non-ideal, behavior has been identified as a "universal" property. ${ }^{33}$ Intrinsically dispersive behavior can be ascribed to a distribution of relaxation times in the system. ${ }^{34}$ From a microscopic point of view correlated forward-backward motion of the ions might also be responsible. ${ }^{35-37}$ Models describing (conductivity) relaxation in real systems account for the effects being expected when structural disorder and Coulomb interactions are present in the system, which may also lead to a structural relaxation of the lattice. ${ }^{38,39}$ Interesting microdynamic considerations more specifically for $\mathrm{LiNbO}_{3}$, which might be useful for ongoing work, were already presented by Halstead in his early NMR paper. ${ }^{19}$

In our measurements the deviation from Debye relaxation is small which corresponds to the fact that effects of structural disorder or distributed jump barrier heights are in general not expected in a single crystal. Additionally, no distinct electrode effects appear at low frequencies showing that the application of $\mathrm{Ag}$ paste on the polished crystal surface yields low-resistance electrodes. The resistance $Z^{\prime}(\omega)$ at the low-frequency intersection of the impedance arc in $Z(\omega)$ plots corresponds to the reciprocal DC plateau value of $Y^{\prime}(\omega)$. Taking into account the sample dimensions, the dc conductivity $\sigma$ can readily be calculated.

The conductivity measurements on a $\mathrm{LiNbO}_{3}$ single crystal were carried out twice with different samples. Each sample was measured in several cycles with ascending and descending temperature values. For the sake of clarity only the data of one sample are depicted in Fig. 5 because both showed the same results. The data were recorded after a first heating to about $1000 \mathrm{~K}$ for several hours. DC conductivities were obtained which range from $2.8 \times 10^{8} \mathrm{~S} \mathrm{~cm}^{-1}$ at $694 \mathrm{~K}$ to $1.3 \cdot 10^{5} \mathrm{~S} \mathrm{~cm}^{-1}$ at $952 \mathrm{~K}$.

For a comparison to the SIMS measurements charge diffusivities, $D_{\sigma}$, are calculated from the dc conductivities using the Nernst-Einstein relation,

$$
D_{\sigma}=\frac{k_{\mathrm{B}} T \sigma}{n q^{2}}
$$

where $n$ denotes the number density of the conducting species, $q=e$ the electrical charge, $k_{\mathrm{B}}$ the Boltzmann constant, and $T$ the temperature. If it is assumed that all $\mathrm{Li}^{+}$ions are involved in the conduction process, $n=N / V$ is simply given by the number of $\mathrm{Li}^{+}$ions per unit cell $N=6$ and the unit cell volume $V=318 \AA^{3}$. Since oxygen ${ }^{40-42}$ and niobium ${ }^{15}$ ion diffusivities are much lower than those of lithium, $\mathrm{Li}^{+}$is assumed to be the only effective charge carrier and the conductivity $\sigma$ can therefore directly be used to calculate $D_{\sigma}$. The results are also plotted in Fig. 4 for comparison. It can be seen that the charge diffusivities are identical within error limits to the tracer diffusivities. Between $694 \mathrm{~K}$ and $952 \mathrm{~K}$ an Arrhenius behavior with an activation energy of $\Delta H_{\sigma}=(1.42 \pm 0.01) \mathrm{eV}$ is found.

Generally, the ratio between tracer and charge diffusivity is given by the Haven ratio $H=D / D_{\sigma}$. In the actual case, a Haven ratio close to unity is found. This again confirms that $\mathrm{Li}$ is the only type of mobile species contributing to conductivity and that strong correlation effects are absent.

\section{Discussion}

In order to understand the $\mathrm{Li}$ diffusion behaviour in the $\mathrm{LiNbO}_{3}$ single crystals under investigation, three enthalpies have to be considered, which might contribute to the activation enthalpy of diffusion, $\Delta H$. These are the enthalpy of $\mathrm{Li}$ migration via a certain defect (vacancy or interstitial), $\Delta H_{\mathrm{m}}$, the enthalpy of formation of this defect, $\Delta H_{\mathrm{f}}$, and finally the enthalpy of defect complex formation at low temperatures, $\Delta H_{\mathrm{c}}$. Since the experimental data can be fitted with a unique Arrhenius straight line, only a single mechanism is dominant over the whole temperature range investigated. Due to the $\mathrm{Li}_{2} \mathrm{O}$ deficient composition of the single crystal, intrinsic defect structures or defect clusters have to be present in order to realize off-stoichiometry. In the literature, there are mainly three models discussed for the intrinsic point defect structures in $\mathrm{LiNbO}_{3}{ }^{13,14,20}$ In model $\mathrm{I}$, two lithium vacancies are compensated by an oxygen vacancy $\left(2 V_{\mathrm{Li}}^{\prime}+V_{\mathrm{O}}^{\bullet \bullet}\right)$, while in model II, niobium antisites are compensated by niobium vacancies $\left(5 \mathrm{Nb}_{\mathrm{Li}}^{\bullet \bullet \bullet \bullet}+4 V_{\mathrm{Nb}}^{\prime \prime \prime \prime \prime}\right)$. The most reliable model (model III) consists of a niobium antisite compensated by four lithium vacancies $\left(\mathrm{Nb}_{\mathrm{Li}}^{\bullet \bullet \bullet \bullet}+4 V_{\mathrm{Li}}^{\prime}\right)$. This model is supported by experimental X-ray and neutron diffraction studies ${ }^{43,44}$ and density functional theory calculations. ${ }^{45}$ As the dominant diffusion 
defect the Li vacancy is assumed and ab inito DFT calculations for the migration enthalpy of single positively charged vacancies in $\mathrm{LiNbO}_{3}$ give $\Delta H_{\mathrm{m}}=1.67 \mathrm{eV}{ }^{13}$

In ref. 46 the following solution reaction is given for $\mathrm{Li}_{2} \mathrm{O}$

$$
\left\langle\mathrm{LiNbO}_{3}\right\rangle \leftrightarrow 3 \mathrm{Li}_{2} \mathrm{O}+4 V_{\mathrm{Li}}^{\prime}+\mathrm{Nb}_{\mathrm{Li}}^{\bullet \bullet \bullet},
$$

where $\Delta E=4.56 \mathrm{eV}$ is the calculated energy of reaction (5) per $\mathrm{Li}_{2} \mathrm{O}$. Considering the equilibrium constant of reaction (5) of

$$
K=a_{\mathrm{Li}_{2} \mathrm{O}}^{3} \times\left[\mathrm{V}_{\mathrm{Li}}^{\prime}\right]^{4} \times\left[\mathrm{Nb}_{\mathrm{Li}}^{\bullet \bullet \bullet \bullet}\right]=\exp \left(-\frac{\Delta G_{\mathrm{r}}}{k_{\mathrm{B}} T}\right)
$$

and the corresponding electro neutrality condition for $\mathrm{Li}_{2} \mathrm{O}$ deficient single crystals

$$
4\left[\mathrm{Nb}_{\mathrm{Li}}^{\bullet \bullet \bullet \bullet}\right]=\left[V_{\mathrm{Li}}^{\prime}\right]
$$

we get for the concentration of lithium vacancies in equilibrium

$$
\left[V_{\mathrm{Li}}^{\prime}\right]=a_{\mathrm{Li}_{2} \mathrm{O}}^{-3 / 5} \times 4^{1 / 5} \times \exp \left(-\frac{1}{5} \frac{\Delta G_{r}}{k_{B} T}\right) .
$$

Here, $\Delta G_{\mathrm{r}}$ is the standard Gibbs energy and $a_{\mathrm{Li}_{2} \mathrm{O}}$ is the activity of $\mathrm{Li}_{2} \mathrm{O}$. Assuming further a temperature independent activity of $\mathrm{Li}_{2} \mathrm{O}$ and neglecting the enthalpy of dissolution of $\mathrm{Li}_{2} \mathrm{O}$ in $\mathrm{LiNbO}_{3},{ }^{41,42}$ we obtain for the formation enthalpy of $\mathrm{Li}$ vacancies,

$$
\Delta H_{\mathrm{f}}=-k_{\mathrm{B}} \frac{\partial \ln \left[V_{\mathrm{Li}}^{\prime}\right]}{\partial(1 / T)}=\frac{1}{5} \Delta H_{\mathrm{r}}=0.91 \mathrm{eV} .
$$

This vacancy formation enthalpy is assumed to play a considerable role at high temperatures where reaction (5) may take place and a modified defect equilibrium can be established by changing the temperature. In this case the sum of the contributions of defect formation and defect migration is expected for the activation enthalpy of diffusion, which is given by $\Delta H=\Delta H_{\mathrm{m}}+\Delta H_{\mathrm{f}}=1.67 \mathrm{eV}+0.91 \mathrm{eV}=2.58 \mathrm{eV}$. This value does not agree with the measured activation enthalpy of $1.33 \mathrm{eV}$.

In contrast, at low temperatures it is expected that defect clusters are formed, where the niobium antisite atom is surrounded by three lithium vacancies in nearest neighbour positions, plus one independent lithium vacancy along the $z$ direction. ${ }^{13,47}$ A possible dissociation of the defect complex can be written as

$$
\left(\mathrm{Nb}_{\mathrm{Li}}^{\bullet \bullet \bullet} 4 V_{\mathrm{Li}}^{\prime}\right) \leftrightarrow \mathrm{Nb}_{\mathrm{Li}}^{\bullet \bullet \bullet}+4 V_{\mathrm{Li}}^{\prime}
$$

with the equilibrium constant

$$
K^{*}=\frac{\left[\mathrm{Nb}_{\mathrm{Li}}^{\bullet \bullet \bullet}\right]\left[V_{\mathrm{Li}}^{\prime}\right]^{4}}{\left[\left(\mathrm{Nb}_{\mathrm{Li}}^{\bullet \bullet \bullet \bullet} 4 V_{\mathrm{Li}}^{\prime}\right)\right]}=K_{0} \exp \left(-\frac{\Delta H_{\mathrm{C}}}{k T}\right)
$$

At temperatures close to room temperature defect complexes in high concentration are expected to be present in order to explain the variation of physical properties within the solid solution range. ${ }^{13}$ Increasing temperature leads to a shift of the equilibrium of eqn (10) to the right and free vacancies are formed which allow diffusion. An upper limit for the fraction of these vacancies is provided by the off-stoichiometry of the crystal, which is about $4 \%$ at the congruent composition. ${ }^{14}$ At the medium range temperatures of our experiment this is the maximum amount of vacancies which can be used as transport vehicles for diffusion. Lowering the temperature should lead to a decrease of the free vacancy concentration and consequently of the diffusivities by complex formation. At present the exact state and number of defect complexes at the temperatures of our measurements are not known. If defect complexes are present in a sufficient amount and if they are converted into $\mathrm{Li}$ vacancies, the activation enthalpy of $\mathrm{Li}$ diffusion should contain the sum of the enthalpy of the conversion reaction (10), as well as the enthalpy of motion of the vacancy. The formation enthalpy/energy of the defect complex discussed above, $\Delta H_{\mathrm{c}}$, was calculated by different authors to be $1.2 \mathrm{eV}^{13}$ and $0.77 \mathrm{eV},{ }^{48}$ respectively. We would get values of $\Delta H=$ $\Delta H_{\mathrm{m}}+\Delta H_{\mathrm{c}}=2.34-2.87 \mathrm{eV}$, which is also inconsistent with the measured activation enthalpy. Consequently, the complexes are almost totally converted and the activation enthalpy of diffusion will be identical to the enthalpy of motion, $\Delta H=\Delta H_{\mathrm{m}}$.

From our experiments an activation enthalpy of ionic motion of $\Delta H_{\mathrm{m}}=1.33 \mathrm{eV}$ is derived, which is in acceptable agreement to the value found by ab initio calculations. ${ }^{13}$ Over the complete investigated temperature range Li vacancies are present and form the dominating defect governing diffusion. This is also valid at temperatures as low as $423 \mathrm{~K}$. The fact that the migration enthalpy is measured in our experiments means that diffusion takes place at a constant vacancy concentration, even if the temperature is changed. This can be explained with a scenario that the dominating defect contribution is realized by reaction (5), however, it is not modified in the temperature range investigated. The single crystal was grown by the Czochralski method and the defect concentration was established during cooling. If temperature is progressively lowered, the rate constant in eqn (6) also becomes lower and the reaction "freezes in" at a certain temperature. This means that a constant vacancy concentration is present, which is not modified during the diffusion anneals, and we have some kind of "structural vacancies". As demonstrated by the pre-annealing experiment this "freezing-temperature" should be higher than $1223 \mathrm{~K}$.

The pre-exponential factor in eqn (3) is than given by

$$
D_{0}=x a^{2} v_{0} \exp \left(\Delta S / k_{\mathrm{B}}\right)
$$

where $a=3.771 \AA^{13}$ is the Li-Li jump distance, $x=\left[V_{\mathrm{Li}}^{\prime}\right] / \mathrm{Li}_{\mathrm{Li}}^{x}=0.04^{14}$ is the mole fraction of $\mathrm{Li}$ vacancies and $\nu_{0} \approx 2.5 \times 10^{13} \mathrm{~s}^{-113}$ is a characteristic vibration frequency. If the entropy of ionic motion is assumed to be $\Delta S \approx 0$, the pre-exponential factor can be calculated according to eqn (12) to be $D_{0}=1.4 \times 10^{-7} \mathrm{~m}^{2} \mathrm{~s}^{-1}$. This is in excellent agreement with the experimentally derived value of $1.7 \times$ $10^{-7} \mathrm{~m}^{2} \mathrm{~s}^{-1}$ within error limits, confirming the suggested model.

In addition, the incorporation of a small amount of impurities in the form of aliovalent cations into the $\mathrm{LiNbO}_{3}$ lattice may play a substantial role. Type and concentration of such impurities are unknown at present. As shown in ref. 48 various impurity incorporation reactions may lead to the extrinsic formation of $\mathrm{Li}$ vacancies. In this case also the migration enthalpy is measured in self-diffusion experiments. Diffusion experiments in single crystals, which were specifically doped, may give further clarification. 
No significant influence of the formation of defect complexes on diffusion is observed. This can be explained by the fact that the formation of these complexes according to reaction (10) sets in for temperatures lower than $423 \mathrm{~K}$. An alternative explanation might be that reaction (10) is not in equilibrium at the temperature under investigation. The corresponding rate constant that governs the establishment of the equilibrium and the formation of complexes might be very small in the temperature domain investigated. Hence, a significant time dependent decrease of the diffusivity might be expected for long annealing times, which, however, is not found up to now. Further insight into this topic might be possible if diffusion measurements will be carried out very close to room temperature, where defect complexes are present, as indicated by measurements of ferroelectric properties. ${ }^{9}$ In order to clarify this open question, a different method of diffusivity determination has to be applied, which is able to determine diffusivities well below $10^{-23} \mathrm{~m}^{2} \mathrm{~s}^{-1}$. Neutron reflectometry might be such a method. ${ }^{49}$

Our measurements provided the first tracer self-diffusivities in $\mathrm{LiNbO}_{3}$ single crystals at temperatures below $773 \mathrm{~K}$. However, in the literature some high-temperature data above $1073 \mathrm{~K}$ are available, which were also obtained by tracer methods about 25 years ago. ${ }^{24}$ The data are also shown in Fig. 4. A higher activation enthalpy of $1.98 \mathrm{eV}$ was found. This can be explained by the fact that in this temperature range significant vacancy formation according to reaction (5) takes place. The activation enthalpy is then given by $\Delta H=\Delta H_{\mathrm{m}}+$ $\Delta H_{\mathrm{f}}=1.33 \mathrm{eV}+0.92 \mathrm{eV} \approx 2.2 \mathrm{eV}$, being close to the measured value. Further self-diffusivities in the hightemperature range are displayed in Fig. 4, which were obtained by NMR by Halstead ${ }^{19}$ and also by conductivity measurements by Metha et $a l .{ }^{20}$ Halstead's data nicely correspond to our charge diffusivity data. The slightly higher activation enthalpies of diffusion of $1.55 \mathrm{eV}$ and $1.46-1.62 \mathrm{eV}$ found by Mehta et al. and Halstead, respectively, might be a hint that around these temperatures vacancy formation according to reaction (5) might start to influence the data. In order to correctly understand the diffusion behaviour it has to be kept in mind that the exact chemical composition of $\mathrm{LiNbO}_{3}$ in its solid solution range is not known for the literature data. This also might contribute to differences in the activation enthalpy.

\section{Conclusion}

We employed tracer diffusivity measurements using SIMS depth profiling and impedance spectroscopy in order to obtain precise data for lithium self-diffusion in $\mathrm{Li}_{2} \mathrm{O}$-deficient $\mathrm{LiNbO}_{3}$ single crystals at low temperatures. In the temperature range between 423 and $773 \mathrm{~K}\left(150-500{ }^{\circ} \mathrm{C}\right)$ diffusion of lithium is governed by a single vacancy mechanism with an activation enthalpy of diffusion of $1.33 \mathrm{eV}$. Lithium diffuses via structural vacancies whose concentration is fixed by a frozen-in defect structure formed during synthesis of the single crystal. Therefore, the measured activation enthalpy of diffusion essentially consists of the migration enthalpy of lithium vacancies. Charge diffusivities derived from conductivity measurements are in good accordance with the tracer diffusivities pointing to a Haven ratio close to one.

\section{Acknowledgements}

Financial support from the Deutsche Forschungsgemeinschaft (DFG) in the framework of the research unit 1277 ('molife') is gratefully acknowledged. Thanks are due to $\mathrm{H}$. Shi (TU Braunschweig) for the determination of the $\mathrm{Li}_{2} \mathrm{O}$ content of the single crystal.

\section{References}

1 V. Gopalan, V. Dierolf and D. A. Scrymgeou, Annu. Rev. Mater. Res., 2008, 37, 449.

2 Properties of Lithium Niobate, ed. K. K. Wong, Inspec, London, 2002.

3 T. Volk and M. Wöhlecke, Lithium Niobate, Springer, Berlin, 2010.

4 S. C. Abrahams, J. M. Reddy and J. L. Bernstin, J. Phys. Chem. Solids, 1966, 27, 997.

5 H. D. Megaw, Acta Crystallogr., Sect. A: Cryst. Phys., Diffr., Theor. Gen. Crystallogr., 1968, 24(6), 583.

6 R. S. Weis and T. K. Gaylord, Appl. Phys. A: Mater. Sci. Process., 1985, 37, 191.

7 P. Lerner, C. Legras and J. Dumas, J. Cryst. Growth, 1968, 3, 231.

8 P. F. Bordui, R. G. Norwood, D. H. Jundt and M. M. Fejer, J. Appl. Phys., 1992, 71, 875.

9 V. Gopalan, T. E. Mitchell, Y. Furukawa and K. Kitamura, Appl. Phys. Lett., 1998, 72, 1981.

10 O. F. Schirmer, O. Thiemann and M. Wohlecke, J. Phys. Chem. Solids, 1991, 52, 185.

11 A. Prokhorov and I. Kuzminov, Physics and Chemistry of Crystalline Lithium Niobate, Hilger, Bristol, 1990.

12 S. C. Abrahams and P. Marsh, Acta Crystallogr., Sect. B: Struct. Sci., 1986, 42, 61.

13 H. Xu, D. Lee, S. B. Sinnott, V. Dierolf, V. Gopalan and S. R. Phillpot, J. Phys.: Condens. Matter, 2010, 22, 135002.

14 J. Shi, H. Fritze, G. Borchardt and K.-D. Becker, Phys. Chem. Chem. Phys., 2011, 13, 6925.

15 D. Birnie III, J. Mater. Sci., 1993, 28, 302.

16 P. Heitjans, M. Masoud, A. Feldhoff and M. Wilkening, Faraday Discuss., 2007, 134, 67.

17 M. Wilkening, D. Bork, S. Indris and P. Heitjans, Phys. Chem. Chem. Phys., 2002, 4, 3246.

18 M. Wilkening and P. Heitjans, Solid State Ionics, 2006, 177, 3031.

19 T. K. Halstead, J. Chem. Phys., 1970, 53, 3427.

20 A. Mehta, E. K. Chang and D. M. Smyth, J. Mater. Res., 1991, 6, 851 .

21 M. Masoud and P. Heitjans, Def. Diff. Forum, 2005, 237-240, 1016.

22 D. Bork and P. Heitjans, J. Phys. Chem. B, 1998, 102, 7303.

23 D. Bork and P. Heitjans, J. Phys. Chem. B, 2001, 105, 9162.

24 V. B. Ptashnik, T. Y. Dunaeva and I. V. Myasnikov, Inorg. Mater., 1985, 21, 1814.

25 H. Schmidt, G. Borchardt, C. Schmalzried, R. Telle, S. Weber and H. Scherrer, J. Appl. Phys., 2003, 93, 907.

26 H. Schmidt, U. Geckle and M. Bruns, Phys. Rev. B: Condens. Matter Mater. Phys., 2006, 74, 045203.

27 E. Hüger, U. Tietze, D. Lott, H. Bracht, E. E. Haller, D. Bougeard and H. Schmidt, Appl. Phys. Lett., 2008, 93, 162104.

28 H. D. Fuchs, W. Walukiewicz, E. E. Haller, W. Dondl, R. Schorer, G. Abstreiter, A. I. Rudnev, A. V. Tikhomirov and V. I. Ozhogin, Phys. Rev. B: Condens. Matter Mater. Phys., 1995, 51, 16817.

29 H. A. Bracht, H. H. Silvestri and E. E. Haller, Solid State Commun., 2005, 133, 727.

30 I. Földvari, K. Polgar, R. Voszka and R. N. Balasanyan, Cryst. Res. Technol., 1984, 19, 1659.

31 Y. Kong, W. Zhang, X. Chen, J. Xu and G. Zhang, J. Phys.: Condens. Matter, 1999, 11, 2139.

32 J. Crank, The Mathematics of Diffusion, Oxford University Press, Oxford, 1975.

33 A. K. Jonscher, Nature, 1977, 267, 673.

34 A. K. Jonscher, J. Mater. Sci., 1978, 13, 553.

35 P. Maass, J. Petersen, A. Bunde, W. Dieterich and H. E. Roman, Phys. Rev. Lett., 1991, 66, 52

36 M. Meyer, P. Maass and A. Bunde, Phys. Rev. Lett., 1993, 71, 573.

37 K. Funke, Solid State Ionics, 1988, 28-30, 100. 
38 P. Maass, J. Petersen and A. Bunde, Phys. Rev. B: Condens. Matter Mater. Phys., 1995, 51, 8164.

39 K. Funke, Prog. Solid State Chem., 1993, 22, 111.

40 P. J. Jorgensen and R. W. Bartlett, J. Phys. Chem. Solids, 1969, 30, 2639.

41 P. Fielitz, G. Borchardt, R. De Souza, M. Martin, M. Masoud and P. Heitjans, Sol. State Sci., 2008, 10, 746.

42 P. Fielitz, O. Schneider, G. Borchardt, A. Weidenfelder, H. Fritze, J. Shi, K. D. Becker, S. Ganschow and B. Bertram, Solid State Ionics, 2011, 189, 1.

43 N. Zotov, H. Boysen, F. Frey, T. Metzger and E. Born, J. Phys. Chem. Solids, 1994, 55, 145.
44 G. S. Zhdanov, S. A. Ivanov, W. V. Kolontsova and A. E. Korneev, Ferroelectrics, 1978, 21, 463.

45 H. X. Xu, D. Lee, J. He, S. B. Sinnott, V. Gopalan, V. Dierolf and S. R. Phillpot, Phys. Rev. B: Condens. Matter Mater. Phys., 2008, 78, 174103. 46 H. J. Donnerberg, S. M. Tomlinson and C. R. A. Catlow, J. Phys. Chem. Solids, 1991, 52, 201.

47 S. Kim, V. Gopalan, K. Kitamura and Y. Furukawa, J. Appl. Phys., 2001, 90, 2949.

48 R. M. Araujo, K. Lengyel, R. A. Jackson, L. Kovacs and M. E. G. Valerio, J. Phys.: Condens. Matter, 2007, 19, 046211.

49 H. Schmidt, M. Gupta, J. Stahn, T. Gutberlet and M. Bruns, Acta Mater., 2008, 56, 464. 